\title{
Transformation of urban planning
}

\author{
Abbas E. M. Khair \\ Omdurman Islamic University, Sudan
}

\begin{abstract}
A starting point of this paper is the notion of a sustainable city, a dominant concept of global development, which assumes the harmonization of societies and activities, in urban planning. Accordingly, urban planning is playing an important role in achieving a sustainable city. The main purpose of this paper is to contribute to the discussion about the "Sustainable city" and concentrates on the theme "planning, development and management". This paper discusses the development of urban societies, through history and states their implications, on urban planning activities. Also it identifies the development of urban planning methods and practices, in order to assess the transformation of urban planning outcomes, from the point of view of a sustainable city.

Keywords: transformation of urban planning, development of urban societies, development of urban planning methods and practices.
\end{abstract}

\section{Introduction}

Planning is a future-oriented activity, which links "scientific and technical knowledge to actions in the public domain" [1]. Planning as a general activity is the making of an orderly sequence of actions that will lead to the achievement of a stated goal or goals [2]. Urban planning is just a sub-class of a general activity called planning; it is concerned with managing and controlling a particular system, the urban system. The field, in particular, focuses on the use of space, shaping the geographical layout of a city, zoning specific areas for development and deciding on the location of major public facilities like utilities and transportation corridors. The fields of urban planning involve the planning, design, operation, and management of infrastructure and resources. It incorporates a collection of spatial and non-spatial data regarding transportation, household, public services and life quality, population and activities for people. The human environment is concerned with change; therefore planning concepts must be dynamic, not static to cope with this transformation. 


\section{Development of urban societies}

Brotchie et al. [3] explained that advanced societies are experiencing a series of technological revolutions, which are in the process of making profound changes in global societies, structures and economy. Spatial patterns, which have characterized previous times, are now vastly different. Pre-industrial society was predominantly dependent on agricultural production, which occurred outside cities. The industrial revolution reversed this pattern of development, with manufacturing production emerging at that time as one of the major activities taking place in cities. The post-industrial era reversed the pattern again, as manufacturing production moved to metropolitan peripheries. A further stage in the evolution process is computer-based technology, which resulted in information societies, which meant a move from manufacturing to services production.

Toffler [4] predicted that the move from manufacturing to services production is an outcome of economic forces. Turnover in consumer preferences is in accordance with rapid life-style changes. The breakdown of central society today is directly linked to the inadequate images of probable futures. He concluded that every society faces not merely a succession of probable futures but an array of possible futures and conflict over preferable futures.

The management of change is the effort to convert certain possibles into probables, in pursuit of agreed preferables, which is based on the humanization of planning. This humanization, moreover, must be reflected in the structures as well. To connect the super-industrial social in an intelligence system with the decisional centers of society must initialize a concern for the quality of life to build an information society.

The concept of an information society has been described by many scientists and futurologists during the last 30 years. Juha Talvitie [5] explained that Webster distinguishes five definitions, from the presented theories, of the information society depending on five main criteria; these are: technological; economy; occupational; spatial; cultural. The technological criterion refers to the development of information and communication technology, and its effects on social development. The economy criterion refers to the development of new products that affect industrial structures. The occupational criterion refers to the development of new types of work places and occupational restructuring. The spatial criterion refers to the development of different types of networks and their effects on the organization of time and space. The cultural criterion refers to the rapid increase in information in social circulation.

Graham and Marvin [6] spoke of electronic spaces and urban places, and they concluded that, as a result of the development of information and communication technologies, the virtual world functions at the same time with the conventional physical settings. Castle [7] has prepared the well-known new spatial theory called: "the social theory of space and the theory of the space of flows". The outcome of the application of such theory in the information age is the network society, as Castle calls it. 


\section{Development of urban planning methods}

Klosterman [8] argued that, as early as the1960s, urban planning emerged as an applied science. In the 1970 s, it moved to focus on the political process. Since the 1980s, urban planning has become a problem-solving process, emphasizing communication. This shift, from applied science to political process to communication, requires an effective tool such as: the Web-Based Public Participation Geographic Information System (WPPGIS). With the increasing importance of public participation in the planning process, more and more groups take part in the planning process. The urban planning decision-making process has come to depend on these groups, with different social, economical and cultural factors. Communication among these groups is central to urban planning decisions.

Hall [2] explained that history definitely proves, even in strong and effective planning systems, that the world rapidly changes in all kinds of ways that planners fail to predict the future. Plans may fail to correspond to reality, even after a very few years. In any event, even if we did know how to control change, in urban systems, to exert pressure effectively, may prove politically infeasible. A planning system may go wrong according to:

1. Rapid increase of knowledge about the external environment may affect planning decisions, ending with an unpredictable result.

2. Complex interrelationship between different levels of a planning system, and between different elements, in the planning situation.

3. The fact that over time human values or at least the values of those actively concerned tend to change.

Mitchell [9] described that the result of the emergence of the electronics revolution is that: "familiar urban patterns have lost their inevitability". He suggests five points, oversimplified as he says, relevant to the design principles of new urban patterns; these are: dematerialization; demobilization; mass customization; intelligent operation; soft transformation. This concept forms a good base for the development of new urban theory. Suggestions made by Mitchell are not in conflict with Castells' theory, but they rather complement each other. At the conclusion of his book "e-topia" Mitchell describes the features of the future town. He emphasizes both the roles of electronic connectivity and the power of place, with unique qualities, both will function interdependently and in complementary manner with each other (Figure 1). According to Mitchell's model the advancement of information and communication technology will give power to the physical places to move towards virtual places either by complementary or by substitutions. And accordingly traditional transportation links will move towards telecommunication links. 


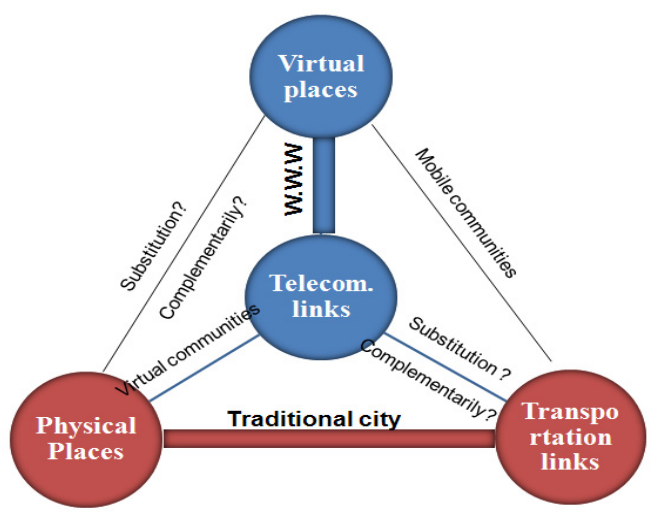

Figure 1: Interaction of physical and virtual places. Source: Mitchell, 1999 [9].

\section{Development of urban planning practice}

\subsection{Shift from government towards governance}

Traditionally, a strong hierarchical approach was assumed in spatial planning, in which the central government was responsible for long-term strategic decisions. Nowadays, self-organizing, complex, and dynamic inter-organizational networks are characteristics of the social political world. Today it is argued that spatial developments are shaped through the interaction of many different stakeholders. Also there is a growing recognition of interdependence between stakeholders as a basic governing principle in a continuous process of negotiating. The shift from government to governance emphasizes social interaction, a system in which collaboration with a range of stakeholders is the central concern. This concept is related to the idea of interactive planning. The shift implies a development of governing styles that entails a broad network of public, semi-public and private stakeholders. Governance seeks to enhance collective goals and is primarily concerned with the coordination and fusion of public and private resources.

\subsection{Shift from sector specific planning towards integrated planning}

A shift from sector planning towards integrated planning could also be signalized in the planning practice. For centuries, the various spatial functions have been divided between several planning sectors, each focused on its own specific part of planning. Urban planning, rural planning, transportation planning, electricity, and water management have remained largely separate sectors. Traditionally, urban planning aimed at the coordination of real estate functions. Until recently, water and environmental functions were barely considered. The problem with this kind of sector division is that interrelationships between the various spatial functions may not be addressed [10]. Due to fragmentation in the planning sectors, the interactions between the various spatial functions and the consequences of these interdependencies are hardly taken into account in spatial planning projects. 


\subsection{Shift from urban planning product to urban planning process}

Traditionally, urban planning (rational planning) had a strong focus on physical results. The emphasis of a rational comprehensive planning concept is on the development of an extensive plan that gives a description of the land use plan showing the desired end-solution. The key criticism of rational comprehensive planning is its over-reliance on the 'objective possibilities' to prescribe the future of an area. A second criticism on rational comprehensive planning was the inflexibility of the master plans. It took years to develop a master plan, while in the meantime the context changed. Master plans were not flexible enough to take new constructions and other developments into account, which implied that newly developed master plans were already outdated before they were implemented.

Inge de Kort et al. [10] stated that the criticism of rational comprehensive planning increased gradually. As a reaction to these points of criticism, attention on the planning process grew. A different line of reasoning in the urban planning literature was developed that concentrated on the planning process. Examples of theories concentrating on urban planning process are communicative planning and interactive planning. These planning approaches stress the attention of the various stakeholders involved in the planning process. Both approaches focus on the goals, aims and interest of stakeholders and on relations between these stakeholders. Communication and participation are key elements in theories concentrating on the planning process. The objective of interactive planning is to reach consensus on a suitable solution between all stakeholders. Due to the negotiation process, this consensus may take the form of a 'package deal'.

Theories concentrating on the planning process are criticized for considering cooperation between stakeholders as a target in itself. In these theories, cooperation is seen as an essential condition to find a solution. The objective of theories concentrating on the planning process is reaching consensus between the stakeholders. The completion of planning activities' content and implementation are, more or less, taken for granted. As a result, these theories lack attention for the final result and its implementation.

\subsection{Shift from 2D urban planning towards 3D visualization}

Under the current development planning system, two-dimensional site plans are commonly used to communicate planning and design information. While the uses of two-dimensional site plans are convenient and adaptable for professionals, they are often unsuitable for the layperson. By nature, we live in a three-dimensional world, visualizing and understanding spatial relationships in three dimensions. The communication of planning and design information in two-dimensional form can often lead to a misinterpretation of design and planning issues. A majority of people find it hard to understand and read two-dimensional maps. To supplement two-dimensional site plans, developers and local authorities often use artist impressions. These impressions are not, however, suited to convey the detail of planning and design issues.

The physical three dimensional models can be of value to the community, it allows them to grasp a better understanding of their area, especially if the model 
is actually built by the community in question. This is the basis of 'Planning for Real', a method of public participation, a technique which provides a means through which the public can have a more meaningful say in local planning matters. One of the criticisms of this technique is that it is time consuming, involves all forms of non-digital consultation, and the level of details of a model created is questionable for detailed development. Accordingly, computers have been seen as changing the planning process since the introduction of the main frame in the 1960s (Figure 2).

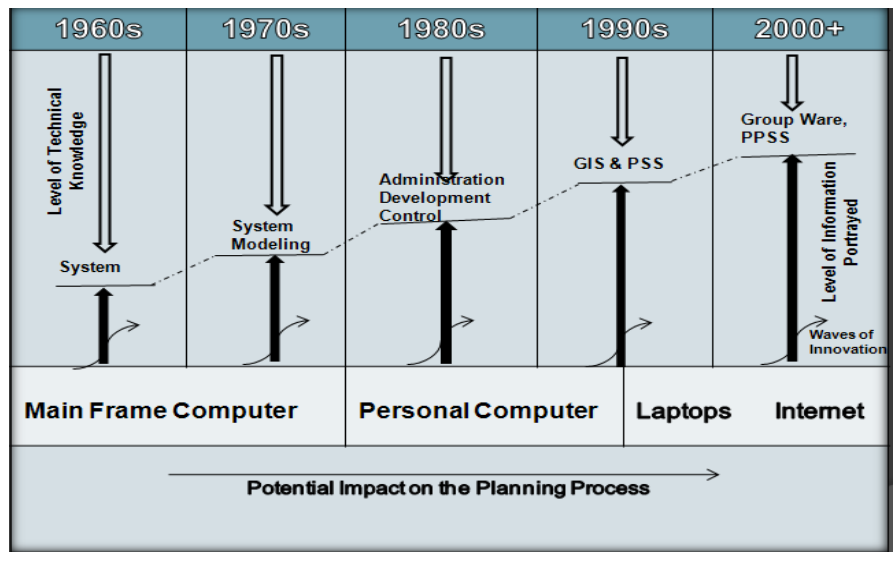

Figure 2: Computer software and technical knowledge in urban planning. Source: Hudson Smith: http://www.casa.ucl.ac.uk/digtialplanning/ [11].

Figure 2 shows the potential impact of computers on urban planning. Obviously, the level of information portrayed is always increasing, while the level of technical knowledge required is decreasing.

\subsubsection{Main frame computers}

The first wave of computing innovation emerged during the early 1960s, characterized by the introduction of large main frame computer systems. At that time the primary concern in planning was system organization, to support the neutral process of rational planning [8]. Main frame computers had the ability to run large amounts of data, through a pre-defined system, with the production of numerical outputs related to spatial analysis. The use of mainframe computers in local authorities was limited mainly to financial departments.

\subsubsection{Personal computers (PCs)}

A greater ability to present and process information characterized the second wave of computing making in the late 1970s and 1980s, with the introduction of the personal computer. The desktop-sized personal computer provided convenient data input and storage utilizing preprogrammed software packages. This type of 
computer started to appear in the USA in local authority planning offices in the late 1970s, but it was not until the mid-1980s that they began to be used widely and became a common occurrence in planning practice.

Computers began to move away from the dominant prior usage of being a solely scientific tool for doing fast arithmetic. Hudson Smith [12] explained that Barrett identified four main areas of computer application in planning systems during the early 1980s:

1. Analytical applications, such as modeling and forecasting, survey and census analysis.

2. Development, maintenance and integration of management databases.

3. Operational management or administrative uses, including planning application processing.

4. Communication-based applications, including mapping and graphics.

The introduction of the new technology into planning arrived with high expectations. The introduction of micro-computers into the planning profession is the solution to all the problems experienced with large scale 'mainframe' computers; every desk can, and should, have one.

\subsubsection{Geographical information systems}

The third wave of innovation, in relation to the planning process, was the introduction of organized information around a geographical location, the Geographical Information System (GIS). The information based on location presented the opportunity for advanced data integration and spatial analysis, a concept developed from the first wave of computing.

Zorica Nedovic [13] identifies four main areas of GIS applications potentially useful for urban planning practice, these are:

1. GIS database developments for planning-related analysis.

2. Integration of geographical technologies with urban models.

3. Building of planning support systems.

4. Facilitating discourse and participation in the planning process.

\subsubsection{New information and communication technologies}

This is the fourth wave of computing in planning, centered on the rise of networked communications, in the form of the Internet. As noted, the past use of computing in planning has been about analysis, models and predictions, whereas the future is about the network. The network is the enabling factor that has the potential to move computing into the heart of the planning system. Also, the network and related new information and communication technology are the enabling presences that gave the potential to move planning away from its traditional characteristic of confrontation towards one of collaboration. It's the ability to communicate and visualize anytime anyplace which leads to the development of a public planning support system (PPSS). The basis to all aspects of groupware and its role in electronic planning, as PPSS, is community and communication. The development of networks and their integration with groupware is the base that 
paved the way towards the concept of electronic planning (e-planning), and web-based planning, allowing the public to access planning activities in both its local and central roles.

4.4.4.1 E-planning concepts Relating to Mitchell's Time-Space Matrix, groupware can be applied for use in urban planning in distinct combinations. Participants are usually assembled in one place at the same time when holding a conventional meeting. GroupWare enables its users to $\log$ in from different locations and interact with each other in a virtual environment. These four combinations are already increasingly pushing planning towards the any time/any place category (Table 1).

Table 1: Urban planning as an urban activity.

\begin{tabular}{|l|l|l|}
\hline & $\begin{array}{l}\text { Same place } \\
\text { (local contact) }\end{array}$ & $\begin{array}{l}\text { Different place } \\
\text { (remote communication ) }\end{array}$ \\
\hline $\begin{array}{l}\text { Same time } \\
\text { (synchronous) }\end{array}$ & $\begin{array}{l}\text { Sameroom planning meetings; } \\
\text { Planning for real exercises; Planning } \\
\text { inquiries. }\end{array}$ & $\begin{array}{l}\text { Digital real-time meeting system, such as } \\
\text { Microsoft's NetMeeting allowing real time } \\
\text { audio and visual communication. Similar } \\
\text { usage as same time/same place. }\end{array}$ \\
\hline $\begin{array}{l}\text { Different } \\
\text { time(asynchronous) }\end{array}$ & $\begin{array}{l}\text { These include bulletin board and } \\
\text { message systems, allowing users to } \\
\text { post a message or comment for reply } \\
\text { ata later time }\end{array}$ & $\begin{array}{l}\text { Asynchronismes communication via } \\
\text { email/HTML pages. Data is } \\
\text { stored for retrieval at a later time via } \\
\text { digital means. }\end{array}$ \\
\hline
\end{tabular}

Table 1 shows that traditional urban planning lies in the 1st quadrant and digital urban planning lies in the 4th quadrant. The move from the 1 st to 4 th quadrant represents the transformation of urban planning as an urban activity.

4.4.4.2 Web-based planning This is defined as a provision of general and areaspecific planning information and services, by an authority via their local government web site. It describes how planners can use the World Wide Web (WWW) to improve community participation, in local planning. On-line public comments (Figure 3) present a good supplement to some classic, traditional ways of public participation. The information provided to users by Web servers is not limited to static files. Several methods exist to forward requests to other server processes that are able to extract information from large database systems and format it for the user (Figure 4). This technique permits simple transaction processing and is the foundation for electronic commerce via the Internet. Software developers have been working to advance the capabilities of the Web by creating special viewers. 


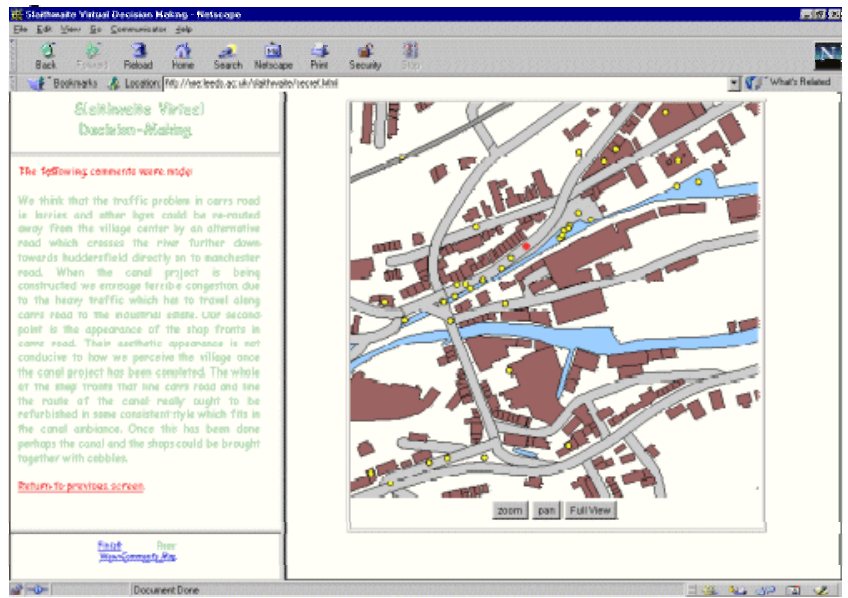

Figure 3: On-line public comments. Source: http:/www.ccg.leeds.ac.uk/ slaithwaite/.

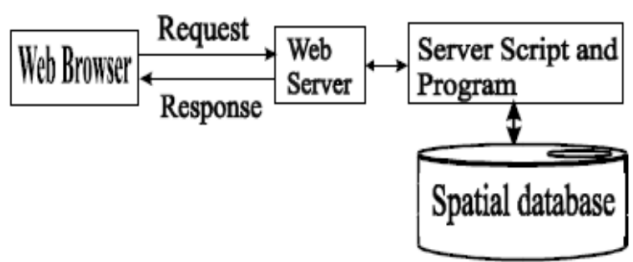

Figure 4: Users' request and server response. Source: http://www.ccg. leeds.ac.uk/slaithwaite/.

\section{Findings}

According to the previous stated literature, and from the point of view of urban planning, it is important to distinguish the following aspects:

1. The development of the information society is taking place in various ways, and at different paces, in all the developed countries, and gradually in developing countries. This development will affect societies and will cause fundamental changes in economic and social life. The development of information and communication technology will create new working life and will reorganize and restructure industrial, public and personal activities and structures. This development in societies and activities will be the main driving force in the innovations of the use of computer in planning. Throughout time, innovations in the use of computers in planning have brought a transformation to planning. Each new innovation or technical advance introduces new software and hardware into public use, capable of solving complex problems, reducing man's working hours and/or enabling previously unachievable tasks to be conducted. 
2. Computers have assisted in the urban planning and urban management process for over four decades. Three elements attained by information and communication technology are essential for urban planning: sufficient resources for intensive use of information; important/necessary data exchange; virtual interactive environment/media that assists multi-user discussions. The way to communicate is increasingly becoming electronic and the rise of the Internet, in particular, as a data source and communication tool during the last decade has freed urban planning from the constraints of working long hours and the reliance on specific locations and times to portray information. Information can now be visualized, communicated and manipulated at any location, any place, and at any time.

3. Four shifts are signaled in urban planning. The first is a shift of reasoning in the urban planning literature. A shift could be shown from the planning product as a concept, towards planning as a process. The second is a shift from sector specific planning towards a more integrated approach. An integrated approach in planning aims at achieving coherence among the various spatial functions to improve the spatial quality and efficiently utilize actions of the available space. The third is the shift from government towards governance; this shift indicates the involvement of a growing number of users. The fourth is a shift from 2D maps towards a 3D visualization.

4. Internet technology is bringing to the table a new wealth of data and parameters, at multiple levels, that were not available to planners before. It is also facilitating citizen access to Internet services at levels never experienced before. Recent developments in new technology have provided considerable challenges and opportunities to improve the management of a planning process by making better use of resources.

5. Indeed, the Internet has had a significant impact on how we plan. It is envisaged that some existing information and communication technology, for example, Geographic Information System (GIS), Virtual Reality (VR) and Computer-Aided Design (CAD), could be used to produce such kinds of new methods for improving and facilitating the transformation of urban planning. In recent years, the number of web-based systems for urban planning using VR and/or GIS is increasing rapidly. In addition, many countries around the world are intending to modernize the planning process or have already initiated such movement.

\section{Conclusions}

The development of urban societies will, according to the earlier discussion, consist of very different development prospects. The human dimension and the environment at a context are important elements, to be considered in the new urban planning theory. So there is an immense need for new urban planning theories. Therefore, the interplay in the creation of urban theories with spatial theories is relevant and important. New spatial and urban theories would form a reliable 
foundation to the development of new planning methods and models. Since life becoming more complex, universal solutions will not work. Therefore, there is a need for the creation of new planning methods and approaches for different types of planning tasks. Such approaches would offer a new way of dealing with the development of new types of communities.

Urban planners have responded to develop urban planning by developing supportive tools, such as network-based geographic information system (GIS) as well as online public participation programs and other types of networking. These technologies have the capacity to automate data handling, reduce planning time, and increase the opportunities for public participation. To incorporate a new aspect into the old planning system is not an easy task. Planners have moved beyond drawing land-use plans to examining the evolution of urban activities, to monitor and analyze urban societal and environmental problems.

\section{References}

[1] Friedman, J. Planning in the public domain: From knowledge action. Princeton, NJ: Princeton University Press, 1987.

[2] Hall, P. Urban and regional planning 4th ed. Routledge, London, 2002.

[3] Brotchie, J. et al. The future of the urban form, impact of technology, London, Routledge, 1983.

[4] Toffler, A. Future shock Pan Books Ltd., London, 1971.

[5] Talvitie, J. The impact of information and communication technologies on urban and regional planning, Espoo, 2003.

[6] Graham, S. and Marvin, S. Telecommunications and the city, electronic spaces, urban places, London Routledge, 2001.

[7] Castle, PPGIS' community mapping of an accessibility map to Enfield Town via the Internet, 2004. Available at http://www.casa.ucl.ac.uk/cjec/msc/index.htm (June 2007).

[8] Klosterman, R. The Appropriateness of Geographic Information Systems for Regional Planning in the Developing World. Computers, Environment and Urban Systems 19, 1: 1-13, 1995.

[9] Mitchell, W. J. E-Topia. Cambridge, MA, the MIT Press, 1999.

[10] Inge de Kort, et al. From urban planning towards strategic integral area development Conference of IAIA SEA Prague: International experience and perspectives in SEA 26-30 September 2005 Prague, Czech Republic, 2005.

[11] Hudson Smith, A.: Digitally distributed urban environment: the prospects for online planning, $\mathrm{PhD}$ thesis, available at: http://www.casa.ucl.ac.uk/digitalplanning/ (2005).

[12] Hudson Smith, A.: "Online Planning: Web based 3D for Public. Participation", London: UCL, Available at: http://www.laserscan.Com /eurosdr /snith.htm (2005) and http://www.casa.ucl.ac.uk/digtialplanning/.

[13] Nedovic, Z. Urban and Regional Planning (Version 12-13-99) URISA Journal, 1999. 